\title{
IMPLEMENTASI PROGRAM SEKOLAH AMAN BENCANA DI SEKOLAH MENENGAH KEJURUAN NEGERI 4 BALIKPAPAN KALIMANTAN TIMUR
}

\author{
Oleh: \\ Rizkia Mutiara Ramadhani, Fitri Andrianti Indah Gustaman, \\ Muhammad Sarip Kodar, IDK Kerta Widanaha \\ Program Studi Magister Manajemen Bencana, Fakultas Keamanan \\ Nasional, Universitas Pertahanan Indonesia \\ Email: rizkiamutiara08@gmail.com
}

\begin{abstract}
Abstrak
Penelitian ini bertujuan untuk mengetahui bagaimana implementasi Sekolah Aman Bencana terhadap sekolah yang terletak di Kalimantan Timur. Sekolah merupakan area publik yang menjadi tempat berkumpulnya masyarakat terutama anak-anak. Sekolah Aman Bencana merupakan salah satu cara untuk melindungi anak-anak dan generasi muda dalam menciptakan kegiatan belajar mengajar yang kondusif serta aman dari ancaman bahaya yang tidak dapat terhindarkan. Pengajaran terkait pengetahuan terhadap bencana dan simulasi evakuasi merupakan hal yang penting sebagai modal kesiapsiagaan yang harus dimiliki seluruh warga sekolah. Sarana dan prasarana yang memadai juga tidak kalah penting sebagai penunjang kesiapsiagaan sekolah. Kesiapsiagaan sekolah menjadi suatu keharusan mengingat Indonesia merupakan negara yang memiliki ancaman bahaya yang tinggi. Penelitian ini menggunakan metode kualitatif dengan penyajian analisis secara deskriptif. Data penelitian dikumpulkan dari komponen sekolah seperti wakil kepala sekolah, guru praktik, serta staff untuk meninjau kesiapsiagaan warga sekolah dalam menghadapi ancaman bahaya di daerah setempat. Hasil dari penelitian ini menunjukkan bahwa Implementasi Sekolah Aman Bencana di SMKN 4 Balikpapan sudah cukup baik karena didukung oleh tingkat kesiapsiagaan yang baik dari warga sekolah.
\end{abstract}

Kata Kunci: kesiapsiagaan sekolah, pengetahuan bencana, sekolah aman bencana, simulasi evakuasi. 
Rizkia Mutiara Ramadhani, Fitri Andrianti Indah Gustaman, Muhammad Sarip Kodar, IDK Kerta Widanaha

\begin{abstract}
This study aims to determine the implementation of the school of Disaster Safe School in East Borneo. School is a public area where people gather, especially children. Safe Disaster Schools are one way to protect children and young people in creating conducive teaching and learning activities and safe from the inevitable threat of danger. Teaching related to knowledge about disasters and evacuation simulations is important as preparedness for all school members. Adequate facilities and infrastructure are no less important to support school preparedness. School preparedness is a must given that Indonesia is a country that has a high threat of danger. This study uses a qualitative method with the presentation of a descriptive analysis. Research data were collected from school components such as vice principals, practical teachers, and staff to review the preparedness of school residents in facing hazard threats in the local area. The results of this study indicate that the implementation of Disaster Safe Schools at SMKN 4 Balikpapan is good enough because it is supported by a good level of preparedness from the school community.
\end{abstract}

Keywords: safe disaster school, school preparedness, disaster knowledge, evacuation simulation.

\title{
Pendahuluan
}

Suatu kejadian dapat dikatakan sebagai sebuah bencana jika manusia mendapatkan dampak yang merugikan dari fenomena yang terjadi baik fenomena alam maupun fenomena non alam (UU Nomor 24 Tahun 2007). Dampak yang merugikan tersebut dapat berupa timbulnya korban jiwa, kerusakan sarana dan prasarana, kerugian materiil dan non materiil, penurunan derajat kesehatan dan lain sebagainya. Bencana yang terjadi dapat muncul karena faktor alam seperti gempa bumi dan gunung meletus. Bisa muncul karena faktor non-alam seperti wabah penyakit. Bencana juga bisa muncul karena faktor manusia, seperti kerusuhan dan terorisme.

Indonesia adalah negara yang pernah mengalami berbagai macam bencana dengan beragam faktor. Mengingat posisi kepulauan Indonesia yang berada di atas rangkaian pertemuan tiga lempeng besar dunia, 
yaitu Eurasia, Indo-Australia, dan Pasifik, otomatias bencana terkait aktivitas tektonik dan vulkanik adalah sebuah konsekuensi logis. Gempa dan tsunami besar juga pernah terjadi di Indonesia, seperti gempa dan tsunami di pantai barat Sumatra pada tahun 2004. Dua letusan gunung terbesar di dunia pernah terjadi di Indonesia, yaitu letusan Gurung Tambora pada tahun dan 1815 letusan Gurung Krakatau pada tahun 1887. Hingga hari ini Indonesia masih menjadi negara dengan gununggunung api teraktif di dunia seperti Gunung Merapi, Gunung Sinabung, dan Gunung Lawu.

Letak Indonesia yang berada di wilayah katulistiwa dengan wilayah yang berpulau-pulau berimplikasi pada dinamika iklim dan cuaca yang beragam dan rentan terhadap dampak dari perubahan iklim. Di Indonesia, bencana akibat perubahan iklim sebagian besar berupa bencana hidrometeorologis. Data BNPB Tahun 2019 menunjukkan bencana banjir, tanah longsor, dan banjir disertai tanah longsor mencapai 3.731 kejadian atau 99\% dari total bencana yang terjadi di Indonesia pada tahun 2019 (Beritasatu, 30 Desember 2020).

Sementara di sebagian wilayah Indoensia terancam banjir dan tanah longsor karena mengalami hujan sepanjang tahun, di sebagian wilayah lain justru bisa mengalami kekeringan. Menurut data yang dihimpun oleh BNPB dari bulan Januari hingga Agustus 2019 terdapat 60 kejadian kekeringan, dengan 1,73 juta penduduk menjadi korbannya. Wilayah kekeringan disebutkan meliputi Jawa Barat, Jawa Tengah, Daerah Istimewa Yogyakarta (DIY), Jawa Timur, Bali, Nusa Tenggara Barat (NTB), serta Nusa Tenggara Timur (NTT) (Berita Satu, 6 September 2019). Topografi Indonesia juga beragam, sehingga tidak jarang kita mendengar kabar adanya bencana tanah longsor, atau banjir bandang. Satu bencana banjir bandang yang terjadi akibat curah hujan tinggi dan topografi adalah banjir di Sentani pada bulan Maret 2019.

Perkembangan masyarakat dan cara hidup masyarakat di Indonesia juga turut memunculkan potensi bencana. Pembangunan yang tidak mempertimbangkan kelestarian lingkungan berdampak pada banjir, 
kenaikan air laut, atau kekeringan. Kebersihan lingkungan yang tidak terperhatikan dengan baik menjadi awal berkembangnya wabah demam berdarah dan penyakit-penyakit lainnya. Pembukaan hutan untuk kepentingan industri daan perkebunan yang serampangan juga berdampak pada kebakaran hutan.

Bentuk bencana lain adalah gagal teknologi. Bencana gagal teknologi yang pernah terjadi seperti kelalaian, kesalahan penggunaan teknologi, kesalahan desain ataupun pengelolaan teknologi juga mengancam masyarakat, contohnya kecelakaan transportasi atau runtuhnya bangunan. Bencana lain yang juga menfancam adalah bencana social. Beragam konflik sosial juga pernah terjadi di Indoensia sebagai implikasi dari beragamnya budaya yang ada di Indonesia, bahkan sebagian konflik besar seperti konflik menjelang kejatuhan Orde Baru tahun 1997, atau konflik antar suku di Kutai menjadi trauma tersendiri bagi korban dan masyarakat luas.

Beragamnya bentuk bencana yang pernah terjadi di Indonesia menandakan bahwa memang wilayah Indonesia sangat rentan akan bencana. Tidak ada satu wilayah yang tidak memiliki potensi bencana, hanya jenis bencana saja yang berbeda di setiap wilayah. Salah satu provinsi di Indonesia yang termasuk daerah rawan terkena bencana adalah Provinsi Kalimantan Timur tepatnya kota Balikpapan. Kota Balikpapan merupakan kota terbesar kedua setelah Samarinda di Provinsi Kalimantan Timur dan menjadi pusat bisnis serta industri yang cukup pesat sehingga menjadikannya sebagai salah satu kota dengan perekonomian terbesar di Kalimantan (BPS, 2018).

Adanya rencana pemerintah dalam pemindahan ibukota negara Indonesia ke wilayah Kalimantan Timur tepatnya Penajam Paser Utara dan Kutai Kartanegara memberikan potensi peningkatan arus kegiatan masyarakat. Hal tersebut dikarenakan adanya Pelabuhan Semayang dan Bandar Udara Internasional Sultan Aji Muhammad Sulaiman di kota Balikpapan sebagai pintu masuk dan keluar utama menuju ibukota baru. 
Berdasarkan topografi dan kondisi wilayahnya, Balikpapan memiliki risiko bencana yang terdiri dari banjir, longsor serta kebakaran hutan dan lahan (Ariyati, 2018). Pada pantauan InaRISK (2019) kota Balikpapan berpotensi memiliki ancaman bencana banjir, gelombang tinggi dan abrasi, kebakaran hutan dan lahan serta kekeringan. Selain itu, adanya fakta bahwa terdapat patahan atau sesar Paternoster di wilayah Kalimantan Timur tentu dapat memberikan risiko terjadinya gempa di wilayah kota Balikpapan (Bachri, 2012).

Kepala Badan Penanggulangan Bencana Daerah (BPBD) Kota Balikpapan ngungkapkan kejadian bencana kebakaran, tanah longsor maupun banjir pada tahun 2016 menujukkan intensitas yang cukup tinggi (Idn Times, 14 September 2019). Hal ini didasari oleh fakta yang diperoleh dari data kejadian bencana yang terjadi pada rentang JanuariDesember 2016. Data menunjukkan kebakaran hutan dan lahan menempati jumlah kejadian tertinggi yaitu 98 kasus, selanjutnya banjir sebanyak 76 kasus, kebakaran pemukiman 35 kasus dan tanah longsor sebanyak 21 kasus. Pada tahun 2019, kebakaran hutan dan lahan menjadi bencana yang paling disoroti karena intensitas kejadiannya meningkat dua kali lipat bahkan dimulai sejak awal tahun 2019 (Glen, 15 Maret 2019).

Dengan demikian, sebagai upaya dalam menekan jumlah kejadian bencana di Balikpapan, Suseno berharap kegiatan simulasi kesiapsiagaan bencana dalam rangka memperingati Hari Kesiapsiagaan Bencana Nasional (HKBN) dapat memberikan edukasi untuk meningkatkan pengetahuan dan kesadaran masyarakat dalam mengatasi situasi darurat bencana (Glen, 2017). Hal itu diperlukan karena strategi penanggulangan bencana akan dapat berjalan dengan efektif apabila penduduk mempunyai pemahaman yang memadai mengenai menejemen dan mitigasi bencana (Sudrajat dan Wibowo, 2016). Mitigasi terbagi menjadi dua jenis yaitu mitigasi struktural dan mitigasi non-struktural. Mitigasi struktural merupakan upaya pengurangan risiko bencana melalui pembangunan fisik serta rekayasa 
teknis bangunan tahan bencana, sedangkan mitigasi non-struktural adalah upaya pengurangan risiko bencana yang bersifat non fisik seperti kebijakan, pemberdayaan masyarakat, penguatan institusi, kepedulian (Sugiharyanto dkk., 2014) Salah satu sasaran dalam penerapan kesiapsiagaan masyarakat dalam menghadapi bencana dilakukan di lingkungan sekolah.

Sekolah merupakan fasilitas umum yang digunakan masyarakat untuk menimba ilmu dan tentu tidak luput berisiko terkena dampak dari kejadian bencana. Sekolah idealnya menjadi tempat yang aman bagi anak dan guru. Pada kegiatan persekolahan setiap harinya paling tidak siswa berada di sekolah selama kurang lebih 8 jam. Data dari Kementerian Pendidikan dan Kebudayaan menyebutkan bahwa 75\% dari total 355.270 bangunan sekolah di Indonesia berada pada wilayah yang berisiko sedang hingga tinggi. Tingkat risiko tersebut dapat meningkat karena banyak bangunan sekolah di Indonesia berusia tua, kurang perawatan dan tidak sedikit yang dibangun tanpa memerhatikan standar bangunan gedung (Lilik, dkk, 2016).

Tingginya tingkat risiko terdampak bencana ini menunjukan bahwa secara nasional sekolah belum sepenuhnya menjadi tempat yang aman dari ancaman bencana bagi anak dan warga sekolah lainnya. Adapun upaya yang bisa dilakukan adalah meningkatkan level mitigasi bencana di sekolah. Semua pihak harus memiliki perhatian terhadap mitigasi bencana di sekolah.

Menilik urgensi mitigasi bencana di tingkat sekolah, serta potensi bencana yang terjadi di kota Balikpapan cukup tinggi, pendidikan kesiapsiagaan bencana di sekolah di Balikpapan merupakan hal penting yang seharusnya diberikan kepada seluruh warga sekolah sebagai bentuk peringatan dini terhadap bencana.

Pendidikan kebencanaan ini, memberikan pengetahuan mengenai tindakan-tindakan yang tepat untuk dilakukan pada tahap sebelum, saat, dan sesudah bencana terjadi. Kurangnya sosialisasi dan sumber informasi tentang pendidikan kebencanaan menjadikan pengetahuan 
warga sekolah terhadap bencana menjadi terbatas. Oleh karena itu, diperlukan suatu upaya yang bertujuan untuk membekali setiap individu di sekolah agar lebih siap dalam menghadapi bencana.

Menurut Undang-Undang Republik Indonesia Nomor 24 Tahun 2007 tentang Penanggulangan Bencana, upaya pengurangan risiko bencana harus dimasukkan ke dalam program pembangunan termasuk dalam bidang pendidikan. Pendidikan menjadi salah satu faktor penentu dalam kegiatan pengurangan resiko bencana. Kesiapsiagaan bencana di sekolah merupakan upaya dan tanggung jawab bersama dari warga sekolah dan para pemangku kepentingan sekolah. Upaya dalam menjamin kesiapsiagaan bencana di sekolah salah satunya dilakukan melalui pelaksanaan program Sekolah Aman Bencana (SAB).

SMKN 4 Balikpapan adalah salah satu sekolah yang telah mendapat predikat sekolah aman bencana (SAB). Hal ini merupakan hasil inisiatif dari pihak sekolah yang menyadari bahwa SMK 4 Balikpapan berada pada zona rawan bencana di Provinsi Balikpapan. Implementasi SAB yang diberlakukan di SMK 4 Balikpapan bertujuan untuk dapat membantu warga sekolah untuk mengurangi dampak akibat bencana atau setidaknya memberikan edukasi dalam menyelamatkan diri ketika bencana terjadi. Dengan demikian, pengkajian diperlukan untuk melihat gambaran secara umum mengenai implementasi program SAB serta mengamati tingkat keberhasilan program tersebut dalam mewujudkan tujuan yang ingin dicapai.

Berdasarkan uraian tersebut di atas, penulis tertarik untuk melakukan penelitian mengenai bagaimana implementasi program sekolah aman bencana (SAB) di SMK 4 Balikpapan. Kedepannya, tulisan ini diharapkan dapat menjadi bahan pengetahuan baru dalam implementasi program SAB serta menjadi dasar evaluasi program SAB di SMK 4 Balikpapan. 
Rizkia Mutiara Ramadhani, Fitri Andrianti Indah Gustaman, Muhammad Sarip Kodar, IDK Kerta Widanaha

\section{Metode Penelitian}

Penelitian ini menggunakan metode kualitatif dengan penyajian analisis secara deskriptif. Menurut Bogdan dan Taylor. Penelitian kualitatif deskriptif adalah sebuah prosedur penelitian yang menghasilkan data deskriptif berupa kata-kata tertulis maupun lisan dari orang-orang yang diamati (Moleong, 2008). Pendekatan yang penulis gunakan yaitu pendekatan field research dengan mengamati fenomena yang terjadi di lapangan serta pencarian data yang diperoleh secara langsung dari tempat penelitian (Moleong, 2008). Penelitian ini dilakukan untuk mengetahui apa saja kesiapan yang telah dilakukan oleh SMK 4 Balikpapan dalam kesiapsiagaannya apabila sewaktu-waktu terjadi bencana.

Rancangan penelitian kualitatif dipilih karena peneliti ingin mengeksplorasi dan memahami implementasi Sekolah Aman Bencana di SMK 4. Penelitian mengenai implementasi suatu program bertujuan untuk menelusuri tindakan yang dilakukan oleh penyelenggara program yang meliputi mengapa tindakan itu dilakukan, bagaimana mekanismenya, apa tujuannya dan bagaimana hasil atau dampaknya. Penelitian ini dilaksanakan pada 27 hingga 28 Februari 2020, dengan lokasi penelitian berada di Sekolah Menengah Kejuruan (SMK) 4 Balikpapan.

Teknik pengumpulan data dilakukan melalui wawancara, observasi dan dokumentasi. Pertanyaan wawancara yang ditanyakan oleh peneliti berjumlah 52 pertanyaan yang terbagi menjadi 8 bagian yaitu pengetahuan, kebijakan manajemen, organisasi tanggap darurat, prosedur keadaan darurat, sumber daya dan sarana, pembinaan dan pelatihan, komunikasi keadaan darurat, serta kontribusi organisasi luar.

Pemilihan informan dalam wawancara menggunakan purposive sampling yaitu penentuan subjek atau objek disesuaikan dengan tujuan dari penelitian (Satori \& Komariah, 2016). Informan yang dimintai keterangan untuk pengumpulan data yaitu pihah-pihak yang terlibat 
langsung dalam pelaksanaan program dan memahami secara mendalam mengenai Sekolah Aman Bencana di SMK 4 Balikpapan, meliputi wakil kepala sekolah, guru bidang kesiswaan, serta beberapa perwakilan guru praktek. Teknik pengumpulan data yaitu melalui wawancara dan observasi yang digunakan untuk menyelidiki implementasi Sekolah Aman Bencana di SMK 4 Balikpapan.

Data-data berupa hasil wawancara dan hasil pengamatan atau observasi yang dikumpulkan selanjutnya dianalisis dengan model analisis data Miles Huberman dan Saldana (2014) dengan mengolah data kualitatif secara interaktif dan terus menerus hingga tuntas sampai data yang diolah telah jenuh.

Tahapan analisis data berdasarkan model Miles, Huberman dan Saldana yang meliputi: pertama, pengambilan/pengumpulan data. Semua sumber yang telah dikumpulkan baik melalui wawancara, observasi dan dokumentasi ditelaah, kemudian direduksi dengan membuat abstraksi dari hasil data yang dipelajari. Pengumpulan data berupa wawancara kepada narasumber dilakukan untuk mengetahui apa saja yang telah dilakukan oleh pihak sekolah sebagai strategi kesiapsiagaan sekolah apabila terjadi bencana.

Kedua, kondensasi data. Pada tahap selanjutnya, peneliti melakukan pemilahan, pengelompokan dan pembuatan abstraksi dari sumber-sumber yang telah diperoleh. Data hasil wawancara dipilah untuk kemudian disajikan. Ketiga, penyajian data. Hasil dari kondensasi data disajikan dalam bentuk teks yang diuraikan/deskriptif. Keempat, Penarikan kesimpulan. Kesimpulan didapatkan setelah semua data yang dihimpun telah melewati langkah analisis sebelumnya. Kesimpulan merupakan jawaban dari rumusan masalah yang sejak awal telah dimanifestasikan oleh peneliti. 


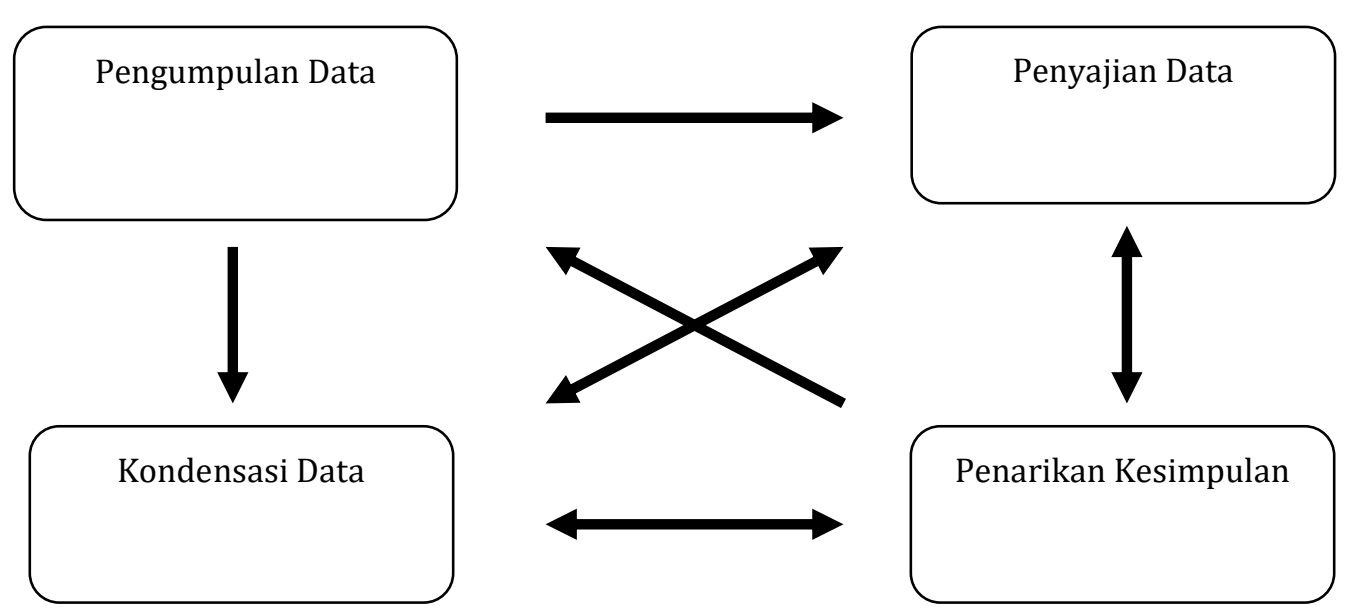

Gambar 1. Model Analisis Data Miles, Huberman dan Saldana (2014)

\section{Pembahasan}

\section{Kesiapsiagaan warga sekolah dalam menghadapi bencana di wilayah Balikpapan Kalimantan Timur.}

SMKN 4 Balikpapan merupakan sekolah yang telah diresmikan menjadi Sekolah Aman Bencana sejak bulan November 2019 lalu. Guruguru dan staff sekolah sudah dibekali dengan pengetahuan serta keterampilan terkait penanggulangan bencana dengan cara pengikutsertaan ke pelatihan-pelatihan kebencanaan dan melakukan sosialisasi di sekolah sebagai bentuk pertanggungjawaban dalam mengikuti pelatihan diluar sekolah.

Siswa juga telah diberikan pengetahuan dasar mengenai apa saja yang menjadi ancaman di sekolah tersebut. Guru praktik wajib memaparkan materi K3 (Keselamatan dan Kesehatan Kerja) sebelum memulai praktikum. Materi yang dipaparkan diantaranya pemakaian seragam mulai dari penutup kepala hingga penutup kaki yang aman dan lengkap serta penggunaan alat yang tepat sehingga tidak terjadi kecelakaan kerja.

Potensi ancaman terbesar di sekolah tersebut adalah api dan petir. Hal ini dikarenakan letak SMKN 4 Balikpapan yang jauh dari gunung api 
dan pantai, sebaliknya sekolah tersebut terletak di dataran yang tinggi sehingga rawan petir. Selain itu, sekolah tersebut memiliki potensi ancaman tertinggi yaitu api sehingga sekolah menjalin kerjasama yang baik dengan Pemadam Kebakaran setempat. Hal ini karena SMKN 4 Balikpapan merupakan sekolah menengah kejuruan yang memiliki kelas tata boga sehingga para siswa seringkali harus menggunakan kompor dalam kegiatan belajar mengajar dikelas.

Sejak diresmikan menjadi Sekolah Aman Bencana, SMKN 4 Balikpapan sudah empat kali melakukan praktik simulasi evakuasi salah satunya simulasi kebakaran dan gempa bumi. Hal ini bertujuan untuk memberikan keterampilan untuk melindungi serta mengevakuasi diri sendiri ketika ada bahaya. Praktik simulasi evakuasi dilakukan atas kerjasama dengan pemadam kebakaran dan BPBD setempat.

Program Sekolah Aman Bencana bertujuan untuk memberikan pengetahuan serta keterampilan kepada siswa terkait dengan kesiapsiagaan dalam menghadapi bencana. Memberikan pengetahuan dan mengajarkan siswa tentang pengetahuan dan keterampilan dalam menghadapi bencana merupakan salah satu bentuk perlindungan terhadap siswa. SMKN 4 Balikpapan memiliki warga sekolah yang dapat dikatakan memiliki kapasitas serta pengetahuan yang baik mengenai bencana. Hal ini sesuai dengan Undang-Undang Nomor 23 Tahun 2002 tentang perlindungan anak yang menyebutkan bahwa pendidikan keamanan merupakan segala kegiatan yang bertujuan untuk menjamin serta melindungi anak dan hak-haknya agar dapat hidup, tumbuh, berkembang, dan berpartisipasi secara optimal sesuai dengan harkat dan martabat kemanusiaan, serta mendapat perlindungan dari kekerasan dan diskriminasi.

SMKN 4 Balikpapan merupakan salah satu Sekolah Aman Bencana yang memiliki kesiapsiagaan bencana yang cukup baik, khususnya bencana kebakaran dan gempa bumi. Pelatihan berupa sosialisasi kebencanaan serta praktik simulasi evakuasi juga telah dilakukan oleh warga sekolah bekerjasama dengan instansi terkait seperti Pemadam 
Kebakaran dan BPBD setempat untuk meningkatkan kesiapsiagaan warga sekolah dalam menghadapi ancaman bencana. Hal ini sesuai dengan teori yang disebutkan oleh Sarwidi (2013) bahwasanya konsep sekolah siaga bencana dimaksudkan sebagai upaya membangun kesiapsiagaan sekolah dan komunitasnya dalam mengantisipasi bencana. Penelitian ini juga sesuai dengan hasil penelitian yang dilakukan oleh Anderson dan King (2005) mengenai siklon tropis rawan di Australia yang menunjukan bahwa kesadaran, kesiapan, serta pengetahuan masyarakat memiliki kontribusi besar dalam pendidikan dan strategi mitigasi terhadap bencana.

\section{Ketersediaan sarana prasarana untuk menunjang penanggulangan bencana di Sekolah Aman Bencana di wilayah Balikpapan Kalimantan Timur.}

SMKN 4 Balikpapan memiliki ancaman bahaya terbesar yaitu api, listrik, dan petir. Maka dari itu sekolah tersebut menyediakan sarana prasarana untuk menunjang pencegahan dan evakuasi apabila terjadi bencana.

Tabel 1. Sarana Sekolah

\begin{tabular}{|l|l|l|}
\hline No. & Jenis Sarana & Keterangan \\
\hline 1 & Rambu-rambu evakuasi & $\begin{array}{l}\text { Digunakan untuk membimbing } \\
\text { warga sekolah ke titik kumpul } \\
\text { melalui jalur evakuasi yang tersebar } \\
\text { di seluruh bangunan sekolah. }\end{array}$ \\
\hline 2 & Titik kumpul & $\begin{array}{l}\text { Terletak di dua titik yaitu di } \\
\text { lapangan sekolah serta lapangan } \\
\text { parkir sekolah. }\end{array}$ \\
\hline 3 & $\begin{array}{l}\text { APAR (Alat Pemadam Api } \\
\text { Ringan) }\end{array}$ & $\begin{array}{l}\text { Alat untuk memadamkan api } \\
\text { apabila terjadi kebakaran ringan di } \\
\text { sekolah }\end{array}$ \\
\hline 4 & $\begin{array}{l}\text { APAB (Alat Pemadam Api } \\
\text { Berat) }\end{array}$ & $\begin{array}{l}\text { Alat untuk memadamkan api } \\
\text { apabila terjadi kebakaran besar di } \\
\text { sekolah }\end{array}$ \\
\hline
\end{tabular}




\begin{tabular}{|c|c|c|}
\hline 5 & Alat penangkal petir & $\begin{array}{l}\text { Alat untuk menangkal petir yang } \\
\text { terletak di atap sekolah. }\end{array}$ \\
\hline 6 & Speaker sentral & $\begin{array}{l}\text { Digunakan untuk memberi perintah } \\
\text { evakuasi apabila listrik masih } \\
\text { menyala. }\end{array}$ \\
\hline 7 & Megaphone & $\begin{array}{l}\text { Digunakan untuk memberi perintah } \\
\text { evakuasi terhadap siswa dan warga } \\
\text { sekolah lainnya untuk berkumpul di } \\
\text { titik kumpul jika terjadi bencana. }\end{array}$ \\
\hline 8 & Lonceng sekolah & $\begin{array}{l}\text { Digunakan untuk memberi perintah } \\
\text { evakuasi apabila seluruh jaringan } \\
\text { komunikasi terputus. }\end{array}$ \\
\hline 9 & Pasir dan karung & $\begin{array}{l}\text { Digunakan untuk mematikan api } \\
\text { apabila terjadi kebakaran ringan di } \\
\text { sekolah. }\end{array}$ \\
\hline 10 & Tandu & $\begin{array}{l}\text { Digunakan untuk membantu } \\
\text { pelaksanaan evakuasi } \\
\text { terjadi bencana dan } \\
\text { mengalami korban } \\
\text { kesadaran, atau tidak } \\
\text { berjalan. }\end{array}$ \\
\hline 11 & Tabung Oksigen & 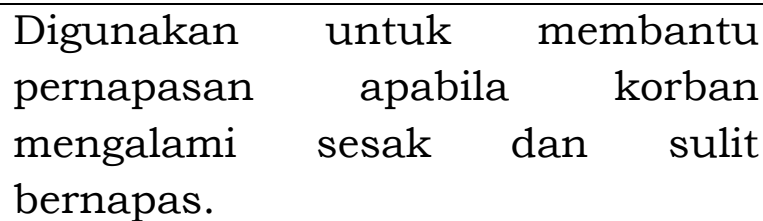 \\
\hline
\end{tabular}

SMKN 4 Balikpapan merupakan salah satu sekolah yang telah diresmikan menjadi Sekolah Aman Bencana. Selain pengajaran terkait pendidikan risiko bencana yang diselipkan dalam kurikulum sekolah di negara yang rentan bencana alam, juga disarankan agar sekolah memiliki sarana yang memadai serta gedung sekolah yang tangguh dan aman terhadap bencana (LIPI-UNESCO/ ISDR, 2006). Hal ini sesuai dengan keadaan bangunan SMKN 4 Balikpapan yang sudah dilengkapi dengan sarana prasarana yang dapat menunjang kesiapsiagaan sekolah dalam menghadapi bencana. Seperti yang telah disebutkan dalam hasil penelitian bahwasanya sekolah telah dilengkapi dengan alat pemadam 
Rizkia Mutiara Ramadhani, Fitri Andrianti Indah Gustaman, Muhammad Sarip Kodar, IDK Kerta Widanaha

api, alat pengeras suara, rambu-rambu evakuasi, serta alat-alat kesehatan untuk menunjang kegiatan evakuasi apabila terjadi bencana.

Dalam Peraturan Pemerintah Nomor 21 Tahun 2008 tentang Penyelenggaraan Penanggulangan Bencana di dalam Pasal 20 termaktub bahwa adanya pengaturan pembangunan, infrastruktur, serta tata bangunan untuk wajib menerapkan aturan standar teknis bangunan yang telah ditetapkan oleh instansi atau lembaga yang berwenang. Adanya sarana dan prasarana di SMKN 4 Balikpapan yang mendukung sarana prasarana dan bangunan sekolah yang telah berstandar sekolah aman bencana.

\section{Penutup}

Implementasi Sekolah Aman Bencana di SMKN 4 Balikpapan sudah cukup baik. Tingkat kesiapsiagaan sekolah tersebut telah diukur dengan menggunakan indikator kesiapsiagaan sekolah diantaranya adalah pengetahuan, kebijakan manajemen, organisasi tanggap darurat, prosedur keadaan darurat, sumberdaya dan sarana, pembinaan dan pelatihan, komunikasi keadaan darurat, serta organisasi luar. Hal ini dibuktikan oleh tingkat kesiapsiagaan warga sekolah SMKN 4 Balikpapan yang dapat dikatakan cukup siap dalam menghadapi bencana.

Tingginya tingkat kesiapsiagaan yang dimiliki oleh warga sekolah SMKN 4 Balikpapan ini didukung oleh adanya dukungan berupa pengetahuan dan keterampilan warga sekolah dalam menghadapi bencana. Diperlukan pula dukungan yang bersifat teknis seperti penyediaan sarana serta prasarana yang mampu mendukung kesiapsiagaan warga sekolah dalam menghadapi ancaman bahaya setempat.

Sebaiknya program implementasi Sekolah Aman Bencana tidak hanya diaplikasikan di SMKN 4 Balikpapan, namun juga diterapkan di sekolah-sekolah lainnya terutama di daerah rawan bencana. Ini bertujuan agar masyarakat lebih siap ketika terdapat ancaman bencana. 
Sekolah merupakan area publik yang menjadi tempat berkumpulnya masyarakat, terutama anak-anak. Jadi alangkah baiknya apabila diberikan pengetahuan serta keterampilan untuk menunjang kesiapsiagaan dalam menghadapi ancaman bahaya di daerah setempat.

\section{Daftar Pustaka}

Anderson, and King, D. (2005). Mitigation of The Impact of Tropical Cyclones in Northern Australia through Community Capacity Enhancement. Mitigation and Adaption Strategies for Global Change, Juli 2005, Volume 10, Issue 3, pp 367-39.

Ariyanti PS, Fathani TF, Wilopo W. (2018). Tesis: Pemetaan Risiko Multi Bencana Kota Balikpapan. Yogyakarta : Universitas Gadjah Mada

Bachri S. (2012). Fase Kompresi di Selat Makassar Berdasarkan Data Geologi Daratan, Seismik Laut dan Citra Satelit. Jurnal Sains dan Teknologi Geologi. Volume 22 (3), hh. 137-144

Badan Pusat Statistika Kota Balikpapan. (2018). PDRB Kota Balikpapan Atas Dasar Harga Berlaku Menurut Lapangan Usaha Tahun 20102018.

Berita Satu. (2019). 1,73 Juta Jiwa Terdampak Kekeringan di 7 Provinsi. https://www.beritasatu.com/irawati-diahastuti/nasional/573650/173-juta-jiwa-terdampak-kekeringan-di7-provinsi

Berita Satu. (2019). 3.731 Bencana di Indonesia Didominasi Hidrometeorologi. $\quad$ https://www.beritasatu.com/feriawanhidayat/nasional/592953/3731-bencana-di-indonesiadidominasi-hidrometeorologi

Glen. (2017). Terjadi 76 Bencana Banjir dan 21 Tanah Longsor di Balikpapan. https://www.inibalikpapan.com/2016-terjadi-76bencana-banjir-dan-21-tanah-longsor-di-balikpapan/

Glen. (2019). Kebakaran Hutan dan Lahan di Balikpapan Meningkat Dua Kali Lipat. https://www.inibalikpapan.com/kebakaran-hutan-danlahan-di-balikpapan-meningkat-dua-kali-lipat/ 
Rizkia Mutiara Ramadhani, Fitri Andrianti Indah Gustaman, Muhammad Sarip Kodar, IDK Kerta Widanaha

Idn times Kalimantan Timur. (2019). Jumlah Kasus Kebakaran Lahan di Balikpapan Meningkat Tajam. Diakses dari https://kaltim.idntimes.com/news/kaltim/muhammad-maulana3/jumlah-kasus-kebakaran-lahan-di-balikpapan-meningkattajam/1

InaRISK. (2020). Peta Risiko Bencana di Kota Balikpapan. Badan Nasional Penanggulangan Bencana (BNPB)

Konsorsium Pendidikan Bencana. (2011). Kerangka Kerja Sekolah Siaga Bencana. Jakarta: Konsorsium Pendidikan Bencana

Lilik K., Lilis S.M., Aminudin H., Elfina R. (2016). Inisiasi Sekolah/madrasah Aman Bencana. Jurnal Riset kebencanaan. 2 (2) 106-116.

LIPI UNESCO/ISDR. (2006). Kajian Kesiapsiagaan Masyarakat dalam Mengantisipasi Bencana Gempa dan Tsunami. Lembaga Ilmu Pengetahuan Indonesia (LIPI). Jakarta

Miles MB, Huberman AM, Saldana J. (2014). Qualitative Data Analysis, A Methods Sourcebook, Edition 3. USA: Sage Publications. Terjemahan Tjetjep Rohindi Rohidi, UI-Press

Moleong, LJ. (2008). Metodologi Penelitian Kualitatif. Bandung : Remaja Rosdakarya

Peraturan Kepala Badan Nasional Penanggulangan Bencana Nomor 4 Tahun 2012

Peraturan Pemerintah Nomor 21 Tahun 2008 tentang Penyelenggaraan Penanggulangan Bencana

Sarwidi, Wantoro, D., dan Suharjo, D. (2013). Evaluasi Sekolah Siaga Bencana (Studi Kasus: SMKN Berbah Kabupaten Sleman, Yogyakarta). Prosiding Seminar Nasional 2013 Menuju Masyarakat Madani dan Lestari. Universitas Islam Indonesia: Yogyakarta.

Satori D, Komariah A. (2014). Metodologi Penelitian Kualitatif. Bandung: Alfabeta

Sudrajat dan Satriyo Wibowo. (2016). Pemahaman Tentang Menejemen Bencana Alam Siswa Sekolah Menengah Pertama. JIPSINDO. No.2 Volume 3 September 2016

Sugiharyanto, Wulandari, T., dan Wibowo S., (2014). Persepsi Mahasiswa Pendidikan IPSI Terhadap Mitigasi Bencana Gempa Bumi. JIPSINDO. 2(1):164-182.

Undang-Undang Nomor 20 Tahun 2003 tentang Sistem Pendidikan Nasional 
JIPSINDO, No.2, Vol.7, September 2020

Undang-Undang Nomor 23 Tahun 2002 tentang Perlindungan Anak

Undang-Undang Nomor 24 Tahun 2007 tentang Penanggulangan Bencana

Zahro, Zulfianti Rosyida, Hana Andriningrum, Elmawati Purnama Sari, Imam Gunawan. (2017). Sekolah Siaga Bencana: Kajian Evaluatif Kesiapsiagaan Sekolah Menghadapi Bencana. Seminar Nasional Pendidikan Fakultas Ilmu Pendidikan Universitas Negeri Malang. 